\title{
Diabetes as a risk factor for stroke. A population perspective
}

\author{
B. Stegmayr, K. Asplund \\ Department of Medicine, University Hospital, Umeå, Sweden
}

Summary Stroke incidence, case fatality and mortality in diabetic patients were compared to non-diabetic subjects in a 35-74-year-old population in northern Sweden (target population 241,000). During an 8-year period, 1,544 stroke events in diabetic patients and 4,826 events in non-diabetic subjects were recorded. The crude incidence of stroke was 1,000 per 100,000 in the diabetic men vs 247 in the non-diabetic men (relative risk 4.1; $95 \%$ confidence interval 3.2-5.2). Among diabetic women, the crude incidence was 757 per 100,000 and 152 in non-diabetic women (relative risk 5.8; $95 \%$ confidence interval 3.7-6.9). The 28-day case fatality among men was similar in the diabetic and non-diabetic stroke patients ( 18.6 vs $17.1 \% ; p=0.311)$, but significantly higher in diabetic women compared with non-diabetic women $(22.2$ vs $17.9 \% ; p=0.02)$. When compared with the non-diabetic population, the overall mortality from stroke in the diabetic population (first and recurrent) was 4.4-times higher in male and 5.1-times higher in the female patients. Hypertension, atrial fibrillation, heart failure or myocardial infarction were all significantly more common in diabetic than in non-diabetic stroke patients. The population attributable risk, a crude estimate of all strokes ascribed to diabetes mellitus, was $18 \%$ in men and $22 \%$ in women. In Sweden, about 50 strokes are annually directly attributed to diabetes in a population of 100,000 in this age group. [Diabetologia (1995) 38: 1061-1068]

Key words Diabetes mellitus, cerebrovascular disorders, case fatality, stroke mortality, stroke incidence, epidemiology, WHO MONICA, population attributable risk, Sweden.
Diabetes mellitus is a well-established risk factor for stroke $[1,2]$ but little is known about its overall significance for stroke in the general population. Patients with diabetes are found to have an excessive risk for cerebral infarction while the risk for subarachnoid haemorrhage and haemorrhage stroke does not seem to be elevated [3-5]. In the Framingham study,

Received: 14 December 1994 and in revised form: 3 March 1995

Corresponding author: Dr. B. Stegmayr, Department of Medicine, University Hospital, S-901 85 Umeå, Sweden Abbreviations: MONICA, Multinational Monitoring of Trends and Determinants in Cardiovascular Disease; ICD, International Classification of Diseases; CT, computerised tomography; $\mathrm{CI}$, confidence interval; $\mathrm{RR}$, relative risk; $\mathrm{CF}$, case fatality. the incidence of cerebral infarction in 45-74-year-old men and women was found to be 2.5 to 3.5 times higher in diabetic patients compared with non-diabetic subjects [6]. Other investigators have observed that diabetic patients have a doubled risk for mortality and morbidity for stroke, that persisted after adjusting for blood pressure, cholesterol, obesity, smoking and excluding individuals with previous myocardial infarction, heart failure or stroke [7]. Besides being a risk factor for stroke, diabetes has been found to have an adverse affect on the short-term as well as the long-term outcome of stroke $[8,9]$.

The aim of the present study was to investigate diabetes from a population perspective as a risk factor for stroke and to estimate its relative contribution to all strokes in the community. 
Table 1. Previously known diabetic patients and patients detected by an oral glucose tolerance test in individuals participating in population surveys 1990 and 1994

\begin{tabular}{|c|c|c|c|c|c|c|}
\hline \multirow{2}{*}{$\begin{array}{l}\text { Age range } \\
\text { (years) }\end{array}$} & \multicolumn{2}{|c|}{ Previously known diabetes } & \multicolumn{2}{|c|}{ Detected at survey } & \multicolumn{2}{|c|}{ Total prevalence } \\
\hline & $n$ & $(\%)$ & $n$ & $(\%)$ & $(\%)$ & $95 \% \mathrm{Cl}$ \\
\hline \multicolumn{7}{|l|}{ Men } \\
\hline $35-44$ & $5 / 379$ & 1.3 & $2 / 184$ & 1.1 & 2.4 & $(0.9-3.9)$ \\
\hline $45-54$ & $9 / 398$ & 2.3 & $4 / 212$ & 1.9 & 4.2 & $(2.2-6.4)$ \\
\hline $55-64$ & $21 / 413$ & 5.1 & $7 / 216$ & 3.2 & 8.3 & $(5.6-11.0)$ \\
\hline $65-74$ & $22 / 192$ & 11.4 & $3 / 92$ & 3.3 & 14.7 & $(9.7-19.7)$ \\
\hline $35-74$ & $57 / 1382$ & 4.1 & $16 / 704$ & 2.3 & 6.4 & $(5.1-7.7)$ \\
\hline \multicolumn{7}{|l|}{ Women } \\
\hline $35-44$ & $5 / 407$ & 1.2 & $0 / 206$ & 0 & 1.2 & $(0.1-2.3)$ \\
\hline $45-54$ & $10 / 416$ & 2.4 & $7 / 236$ & 3.0 & 5.4 & $(3.2-7.6)$ \\
\hline $55-64$ & $15 / 417$ & 3.6 & $6 / 215$ & 2.8 & 6.4 & $(4.1-8.7)$ \\
\hline $65-74$ & $11 / 193$ & 5.7 & $9 / 104$ & 8.7 & 14.4 & $(9.4-19.4)$ \\
\hline $35-74$ & $41 / 1433$ & 2.9 & $22 / 761$ & 2.9 & 5.8 & $(4.6-7.0)$ \\
\hline
\end{tabular}

\section{Subjects and methods}

The two northern-most counties in Sweden together constitute one of the 39 collaborating centres in the World Health Organisation (WHO) MONICA Project (Multinational Monitoring of Trends and Determinants in Cardiovascular Disease). The main objective of this prospective project is to assess how changes in the incidence of coronary heart disease and cerebrovascular disease over a 10-year period relate to changes in cardiovascular risk factors in the population. The northern Sweden MONICA study covers a sparsely populated area of $154,000 \mathrm{~km}^{2}$, with a total population of 510,000 .

Population surveys. Prevalence of diabetes (known diabetes and diabetes diagnosed by an oral glucose load) was estimated from two population surveys performed in 1990 and 1994. The study population was selected by stratified randomisation for age and sex (35-44, 45-54, 55-64 years). The population survey in 1994 also included 65-74-year-old men and women. The target population in the 1990 survey was 193,168 in the 35-64 year age group, and in the 1994 survey it was 243,663 in the 35 74 year age group. In each 10-year stratum, 250 men and 250 women were selected from continuously updated population registers. The individuals were invited by letter to participate in a health survey. A reminder letter was sent if the person did not attend on the first invitation. Of the 1,500 eligible and invited people in 1990, 1,236 participated, a response rate of $82.4 \%$. The corresponding figures for 1994 were 1,579 out of 2,000 , a response rate of $79.0 \%$. A questionnaire on smoking habits, previous cardiovascular diseases and previously known diabetes was filled in by the participants. Of all participants in the two surveys, 98 stated they had diabetes. From the remaining 2,717 , a randomly-selected subsample of 1,472 men and women underwent a glucose tolerance test after an overnight fast.

Glucose $(75 \mathrm{~g})$ was dissolved in $300 \mathrm{ml}$ water and the solution was ingested within $5 \mathrm{~min}$. A venous blood sample was taken in natriumfluoride tubes immediately before the glucose load and after $2 \mathrm{~h}$. The samples were analysed by a hexokinase method (Boehringer Mannheim Automated Analysis for BM/ Hitachi System 717, Boehringer Mannheim, Mannheim, Germany). According to the WHO criteria, subjects were classified as diabetic if the fasting plasma value exceeded $7.7 \mathrm{mmol} / 1$ or the 2-h plasma glucose was above $11.0 \mathrm{mmol} / \mathrm{l}$ [10].

Stroke registration. During an 8-year study period (1985-1992), all acute strokes in both men and women aged 35-74 years were included. The study population for stroke registration and risk factor surveys was the same; it was 240,727 in 1989 (mid-year). All hospital discharge records, general practitioner reports and death certificates with International Classification of Diseases (ICD) codes 430-438 were screened for acute events and validated (methods and definitions have been presented elsewhere) $[11,12]$. In short, stroke was defined according to the WHO criteria and stroke cases were registered in a standardised manner according to the MONICA manual [13]. Transient ischaemic attacks, subdural haemorrhages, traumatic intracerebral haemorrhages and lesions caused by brain tumours were excluded. Since diabetes has not been shown to be a risk factor for subarachnoid haemorrhage [3], such patients were excluded from all attack rate, incidence and mortality calculations in the present study. During the study period, a total of 200 men and 280 women had subarachnoid haemorrhage. Only 8 of $905(0.9 \%)$ diabetic men and 6 of $653(0.9 \%)$ diabetic women had subarachnoid haemorrhage compared to 192 of $3,195(6.0 \%)$ men and 274 of $2,097(13.1 \%)$ women without diabetes. The proportion of diabetic patients among subarachnoid haemorrhage patients was 14 of $480(2.9 \%)$; men and women together.

Each stroke case was classified into one of three categories, "definite stroke", "unclassifiable" or "not stroke" based on the available background information. Unclassifiable events were mostly fatal cases ascertained from the death certificate diagnoses with sparse or no information on the clinical event.

Fatal cases were subjects who died within 28 days from onset of stroke. In accordance with the terminology agreed upon by the MONICA collaborators [14], "attack rate" describes all events regardless of whether the subjects had a previous event. "Incidence" refers to first ever stroke. When giving attack and incidence rates, only cases classified as "definite stroke" have been included in data on non-fatal events, whereas data on fatal events also include cases that were "unclassifiable" [14].

Classification of subtypes of acute stroke, according to the MONICA manual, was based on the following findings (ICD9 codes in parentheses): subarachnoid haemorrhage (430): bloodstained cerebrospinal fluid and an aneurysm or an arteriovenous malformation found on angiography or positive finding on computerised tomography (CT) scan or necropsy; intracerebral haemorrhage (431): positive finding on CT scan or at necropsy; brain infarction (434): no signs of haemorrhage on CT scan or at necropsy; unspecified stroke (436): not investigated by CT scan or necropsy.

Information on any medical history of diabetes, stroke, hypertension, myocardial infarction, atrial fibrillation and car- 
Table 2. Total number of diabetic and non-diabetic stroke patients in the 35-74-year age group, 1985 through 1992 in northern Sweden

\begin{tabular}{|c|c|c|c|c|c|}
\hline \multirow[t]{2}{*}{$\begin{array}{l}\text { Age range } \\
\text { (years) }\end{array}$} & \multicolumn{2}{|c|}{ Diabetic patients } & \multicolumn{2}{|c|}{$\begin{array}{l}\text { Non-diabetic } \\
\text { patients }\end{array}$} & \multirow{2}{*}{$\begin{array}{l}\text { Total } \\
n\end{array}$} \\
\hline & $n$ & $(\%)$ & $n$ & $(\%)$ & \\
\hline \multicolumn{6}{|l|}{ Men } \\
\hline $35-44$ & 13 & $(14.6)$ & 76 & $(85.4)$ & 89 \\
\hline $45-54$ & 71 & $(23.5)$ & 231 & $(76.5)$ & 302 \\
\hline $55-64$ & 187 & (18.4) & 828 & $(81.6)$ & 1015 \\
\hline $65-74$ & 626 & $(22.4)$ & 1868 & $(77.6)$ & 2494 \\
\hline Total & 897 & $(23.0)$ & 3003 & $(77.0)$ & 3900 \\
\hline \multicolumn{6}{|l|}{ Women } \\
\hline $35-44$ & 8 & $(13.6)$ & 51 & $(86.4)$ & 59 \\
\hline $45-54$ & 15 & (11.8) & 112 & $(88.2)$ & 127 \\
\hline $55-64$ & 104 & (20.9) & 393 & $(79.1)$ & 497 \\
\hline $65-74$ & 520 & $(29.1)$ & 1267 & $(70.9)$ & 1787 \\
\hline Total & 647 & $(26.2)$ & 1823 & (73.8) & 2470 \\
\hline
\end{tabular}

Numbers in parentheses show \% of diabetic and non-diabetic patients

diac failure was obtained from hospital records or, in non-hospitalised fatal cases from medical records from primary health care centres. In 56 cases no information was available on diabetes and previous stroke; these subjects were excluded in the analyses. Diabetes was diagnosed during the hospital stay in 57 patients and they were analysed separately.

\section{Statistical analyses}

The population size changed only slightly over the years. In 1985 the total population in the 35-74 year age range was 238,948 and in 1992 it was 245,116 . Calculations of attack rates and incidence were based on the population in 1989. The total number of diabetic individuals in the population was estimated from the prevalence of diabetic subjects found in the population surveys.

The $95 \%$ confidence intervals (CI) were calculated according to the binomial distribution for the number of events within the age groups. The Mantel-Haenszel chi-square statistics or Fisher's exact test were used to test differences in proportions.
Confidence intervals (CI) for relative risks were calculated according to Epi-Info [15].

Population attributable risk (also termed aetiologic fraction) was estimated as described by Armitage and Berry [16].

\section{Results}

Diabetes in the population. In 1990 (35-64 year age group), $3.4 \%$ (42 of 1236) of the participants in the population survey had previously known diabetes and an additional $0.8 \%$ (5 of 631 participants) were found to have an undiagnosed diabetes by an oral glucose tolerance test. In 1994, the upper age limit was extended to 74 years. Of the participants in this survey, $3.6 \%$ (56 of 1,579) declared they had diabetes and another $4.0 \%$ (33 of 834) were found by the glucose tolerance test to have diabetes. Table 1 shows the age-specific diabetes prevalence in northern Sweden in men and women.

Stroke in the population. During the 8 years, 1985 through 1992, 3,900 men and 2,470 women in the 3574 year age range fulfilled the MONICA criteria for acute stroke (both first ever and recurrent). In total, 680 men died within 28 days after onset, a case fatality of $17.4 \%$. The corresponding figure for women was 471 deaths, a 28 -day case fatality of $19.1 \%$.

In 56 fatal events and 2 non-fatal events ( 40 men and 18 women) it was not possible to obtain information on diabetes and previous stroke. Most of these events $(70 \%)$ occurred outside a hospital. They comprised $0.9 \%$ of all stroke events, and were excluded from this study.

During hospitalisation for stroke, 57 patients were diagnosed with diabetes, previously not known to the patient. Of the 35 men, 2 died within 28 days and of the 22 women, 3 died. These patients with previously unknown diabetes constituted $1.2 \%$ of all nondiabetics and $3.7 \%$ of the diabetic patients and be-

Table 3. Crude stroke attack rate and incidence per 100,000 per year with $95 \%$ CI in diabetic and non-diabetic patients in 10 -year age groups

\begin{tabular}{|c|c|c|c|c|c|c|c|c|}
\hline \multirow{2}{*}{$\begin{array}{l}\text { Age range } \\
\text { (years) }\end{array}$} & \multicolumn{4}{|c|}{ Attack rate (all stroke events) } & \multicolumn{4}{|c|}{ Incidence (first ever) } \\
\hline & $\begin{array}{l}\text { Diabetic } \\
\text { patients }\end{array}$ & $(95 \% \mathrm{CI})$ & $\begin{array}{l}\text { Non-diabetic } \\
\text { patients }\end{array}$ & $(95 \% \mathrm{CI})$ & $\begin{array}{l}\text { Diabetic } \\
\text { patients }\end{array}$ & $(95 \% \mathrm{CI})$ & $\begin{array}{l}\text { Non-diabetic } \\
\text { patients }\end{array}$ & $(95 \% \mathrm{CI})$ \\
\hline \multicolumn{9}{|l|}{ Men } \\
\hline $35-44$ & 180 & $(0-451)$ & 24 & $(8-40)$ & 159 & $(0-413)$ & 23 & $(8-38)$ \\
\hline $45-54$ & 692 & $(237-1147)$ & 96 & $(61-131)$ & 498 & $(112-884)$ & 84 & $(51-117)$ \\
\hline $55-64$ & 1041 & $(619-1463)$ & 417 & $(337-497)$ & 760 & $(400-1120)$ & 314 & $(244-384)$ \\
\hline $65-74$ & 2271 & $(1766-2776)$ & 1174 & $(1023-1325)$ & 1518 & (1105-1931) & 844 & $(716-972)$ \\
\hline $35-74$ & 1454 & $(1185-1723)$ & 331 & $(299-365)$ & 1000 & $(777-1223)$ & 247 & $(218-276)$ \\
\hline \multicolumn{9}{|l|}{ Women } \\
\hline $35-44$ & 230 & $(0-681)$ & 18 & $(4-32)$ & 207 & $(0-635)$ & 15 & $(2-28)$ \\
\hline $45-54$ & 118 & $(0-286)$ & 49 & $(23-75)$ & 93 & $(0-243)$ & 40 & $(17-63)$ \\
\hline $55-64$ & 858 & $(422-1294)$ & 190 & $(137-243)$ & 524 & $(183-865)$ & 151 & $(104-198)$ \\
\hline $65-74$ & 1797 & $(1360-2234)$ & 724 & $(611-737)$ & 1134 & (787-1481) & 527 & $(431-623)$ \\
\hline $35-74$ & 1168 & $(914-1422)$ & 202 & $(176-228)$ & 757 & $(552-962)$ & 152 & $(129-175)$ \\
\hline
\end{tabular}


Table 4. 28-day case fatality with $95 \%$ CI in diabetic and non-diabetic patients in 10-year age groups. Based on all stroke events during 8 years

\begin{tabular}{|c|c|c|c|c|c|c|c|c|c|c|c|c|}
\hline \multirow{3}{*}{$\begin{array}{l}\text { Age } \\
\text { range } \\
\text { (years) }\end{array}$} & \multicolumn{6}{|c|}{ All strokes } & \multicolumn{6}{|c|}{ First ever strokes } \\
\hline & \multicolumn{3}{|c|}{ Diabetic patients } & \multicolumn{3}{|c|}{ Non-diabetic patients } & \multicolumn{3}{|c|}{ Diabetic patients } & \multicolumn{3}{|c|}{ Non-diabetic patients } \\
\hline & $n$ & $\%$ & $(95 \% \mathrm{CI})$ & $n$ & $\%$ & $(95 \% \mathrm{CI})$ & $n$ & $\%$ & $(95 \% \mathrm{CI})$ & $n$ & $\%$ & $(95 \% \mathrm{CI})$ \\
\hline \multicolumn{13}{|l|}{ Men } \\
\hline $35-44$ & $2 / 13$ & 15.4 & $(0-34.4)$ & $3 / 76$ & 3.9 & $(0-8.3)$ & $2 / 12$ & 16.7 & $(0-37.8)$ & $3 / 71$ & 4.2 & $(0-8.9)$ \\
\hline $45-54$ & $3 / 71$ & 4.2 & $(0-8.9)$ & $31 / 231$ & 13.4 & $(9.0-17.8)$ & $1 / 51$ & 2.0 & $(0-5.9)$ & $27 / 202$ & 13.4 & $(8.7-18.1)$ \\
\hline $55-64$ & $23 / 187$ & 12.3 & $(7.6-16.9)$ & $128 / 828$ & 15.5 & $(12.9-17.9)$ & $16 / 137$ & 11.7 & $(6.3-17.1)$ & $92 / 624$ & 14.7 & $(7.5-21.9)$ \\
\hline $65-74$ & $139 / 626$ & 22.2 & $(18.9-25.5)$ & $351 / 1868$ & 18.8 & $(17.0-20.6)$ & $79 / 416$ & 19.0 & $(15.2-22.8)$ & $225 / 1342$ & 16.8 & $(14.8-18.8)$ \\
\hline $35-74$ & $167 / 897$ & 18.6 & $(16.1-21.1)$ & $513 / 3003$ & 17.1 & $(15.7-18.5)$ & $98 / 616$ & 15.9 & $(13.0-18.8)$ & $347 / 2239$ & 15.5 & $(14.0-17.0)$ \\
\hline \multicolumn{13}{|c|}{ Women } \\
\hline $35-44$ & $1 / 8$ & 12.5 & $(0-35.4)$ & $2 / 51$ & 3.9 & $(0-9.2)$ & $1 / 7$ & 14.3 & $(0-40.2)$ & $2 / 44$ & 4.5 & $(0-10.6)$ \\
\hline $45-54$ & $1 / 15$ & 6.7 & $(0-19.4)$ & $15 / 112$ & 13.4 & $(7.1-19.7)$ & $0 / 12$ & 0 & & $13 / 93$ & 14.0 & $(6.9-21.1)$ \\
\hline $55-64$ & $23 / 104$ & 22.1 & $(14.1-30.1)$ & $53 / 393$ & 13.5 & $(10.1-16.9)$ & $15 / 73$ & 20.5 & $(11.3-29.8)$ & $43 / 312$ & 13.8 & $(10.0-17.6)$ \\
\hline $65-74$ & $119 / 520$ & 22.9 & $(19.3-26.5)$ & $257 / 1267$ & 20.3 & $(18.1-22.5)$ & $57 / 328$ & 17.4 & $(13.3-21.5)$ & $171 / 921$ & 18.6 & (16.1-21.1) \\
\hline $35-74$ & $144 / 647$ & 22.2 & $(19.0-25.4)$ & $327 / 1823$ & 17.9 & $(16.1-19.7)$ & $73 / 420$ & 17.4 & $(13.8-21.0)$ & $229 / 1370$ & 16.7 & $(14.7-18.7)$ \\
\hline
\end{tabular}

cause of uncertainty about the accurancy of the diagnosis, they were not included in the analyses.

Diabetes in stroke patients. Of all male stroke patients, $23.0 \%(897$ of 3,900$)$ had diabetes at the onset of stroke. In men with first ever stroke, $21.6 \%(616$ of 2,855$)$ were diabetic patients. In women, $26.2 \%$ $(647$ of 2,470$)$ of all stroke patients had diabetes, and in women with first ever stroke $23.5 \%$ (420 of 1,790 ) were diabetic patients. Table 2 shows the proportion of diabetic patients in the different age groups.

Intracerebral haemorrhage was significantly less prevalent in patients with diabetes (97 of 1,544; $6.3 \%$ ) compared to those without diabetes (719 of $4,826 ; 14.9 \%) p<0.0001$. In patients with intracerebral haemorrhage, 97 were diabetic out of 819 $(11.9 \%)$, compared to 1,447 of $5,554(26.1 \%)$ with diabetes among patients with non-haemorrhagic stroke; $p<0.0001$.

Of all diabetic stroke events, $37(4.1 \%)$ occurred in men and $13(2.0 \%)$ in women with insulin-dependent diabetes. Information on the type of diabetes was not available for $27(3.0 \%)$ of the men and for $10(1.5 \%)$ of the women. Of the diabetic stroke patients in the 35-44 year age group, $76 \%$ (16 of 21 ) had insulin-dependent diabetes and in $14 \%$ ( 3 of 21 ) the type of diabetes was unknown.

The proportion of recurrent strokes out of all strokes was significantly higher in diabetic than in non-diabetic subjects. In men, this proportion was 281 out of $897(31.3 \%)$ among the diabetic patients, and 764 out of $3,003(25.4 \%)$ in the non-diabetic subjects, respectively; $p=0.0006$ and, in women, 227 out of $647(35.1 \%)$ vs 453 of $1,823(24.9 \%)$ respectively; $p<0.0001$. Of all recurrent strokes in men, 281 of $1,045(26.9 \%)$ affected diabetic patients, the corresponding proportion in first ever strokes being 616 diabetic patients out of 2,855 (21.5\%). In women, 227 of $680(33.4 \%)$ recurrent events affected diabetic pa- tients, compared to 420 out of $1,790(23.5 \%)$ with first ever stroke events.

Stroke attack rate and incidence. Table 3 shows the age- and sex-specific stroke attack rate (all events) and incidence (first ever) for the diabetic and the non-diabetic populations. Age-specific attack rate and incidence of stroke was consistently higher in diabetic than in non-diabetic patients. The crude attack rate in diabetic men aged 35-74 years was 1,454 per 100,000 per year and in non-diabetic men it was 331 per 100,000 , yielding a relative risk (RR) of 4.4 (95\% CI 3.6-5.4). The crude incidence was 1,000 per 100,000 in diabetic men and 247 in non-diabetic men (RR 4.1; $95 \%$ Cl 3.2-5.2).

The crude attack rate in diabetic women was 1,168 per 100,000 per year and in non-diabetic women 202 per 100,000 per year, corresponding to a RR of 5.8 (95\% CI 4.5-7.4). The incidence was 757 per 100,000 in diabetic women and 152/100,000 in non-diabetic women (RR 5.1; $95 \%$ CI 3.7-6.9).

Standardised to the 1989 population, the attack rate for diabetic men was 1,003 per 100,000 per year (95\% CI 776-1,230) and for non-diabetic men 350 per 100,000 per year (95\% CI 315-385); (RR of 2.9). Corresponding figures for women were 643 per 100,000 per year $(95 \%$ CI 449-837) in diabetic and 213 (95\% CI 185-241); (RR 3.0) in non-diabetic women.

Case fatality and mortality rates. The 28-day case fatality increased with age in men and women in both the diabetic and the non-diabetic groups. Table 4 shows the case fatality rates in men and women. The overall case fatality in the 35-74 year age range was $17.1 \%$ in non-diabetic men and $18.6 \%$ in diabetic men $(p=0.311)$ Also in men with first ever stroke, the case fatality was similar in non-diabetic and diabetic men ( 15.9 vs $15.5 \% ; p=0.852$ ). 
Table 5. Numbers of concomitant disorders in diabetic and non-diabetic stroke patients and the relative risk (RR) with $95 \%$ confidence intervals $(95 \% \mathrm{CI}$ ) for diabetic vs non-diabetic patients

\begin{tabular}{|c|c|c|c|c|c|c|}
\hline \multirow[t]{3}{*}{ Disorder } & \multicolumn{6}{|l|}{ Patients } \\
\hline & \multicolumn{2}{|l|}{ Diabetic } & \multicolumn{2}{|c|}{ Non-diabetic } & \multicolumn{2}{|c|}{ Relative risk } \\
\hline & Number & $\%$ & Number & $\%$ & RR & $(95 \% \mathrm{CI})$ \\
\hline \multicolumn{7}{|l|}{ Men } \\
\hline Atrial fibrillation & $122 / 893$ & 13.7 & $330 / 2984$ & 11.1 & 1.24 & $1.02-1.50$ \\
\hline Hypertension & $403 / 851$ & 47.4 & $990 / 2823$ & 35.1 & 1.35 & $1.24-1.47$ \\
\hline Heart failure & $112 / 895$ & 12.5 & $142 / 2995$ & 4.7 & 2.64 & $2.08-3.34$ \\
\hline Myocardial infarction & $241 / 889$ & 27.1 & $501 / 2951$ & 17.0 & 1.60 & $1.40-1.83$ \\
\hline \multicolumn{7}{|l|}{ Women } \\
\hline Atrial fibrillation & $109 / 641$ & 17.0 & $190 / 1859$ & 10.2 & 1.42 & $1.14-1.77$ \\
\hline Hypertension & $379 / 680$ & 55.7 & $747 / 1823$ & 41.0 & 1.36 & $1.25-1.48$ \\
\hline Heart failure & $114 / 644$ & 17.7 & $94 / 1813$ & 5.2 & 3.41 & $2.64-4.42$ \\
\hline Myocardial infarction & $92 / 645$ & 14.3 & $167 / 1815$ & 9.2 & 1.55 & $1.22-1.97$ \\
\hline
\end{tabular}

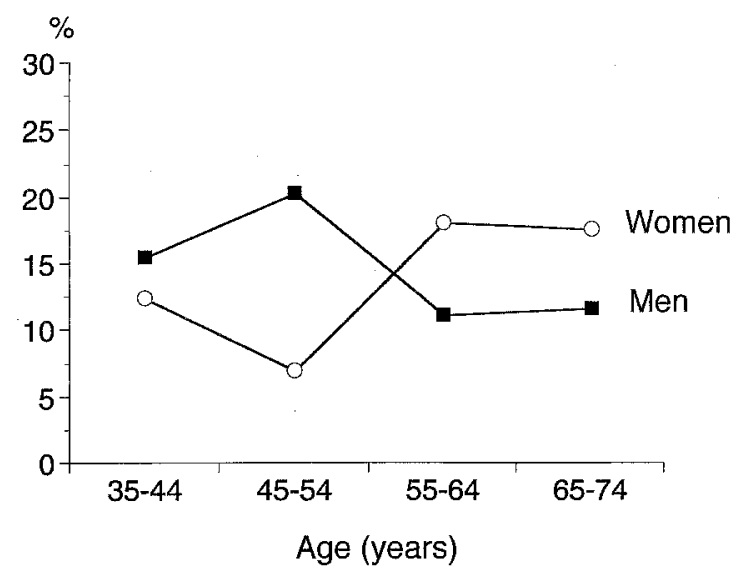

Fig. 1. Population attributable risk for stroke in men and women in different age groups

The overall 28-day case fatality in the 35-74 year age group was significantly ( $p=0.0191)$ higher for diabetic women (CF $22.2 \%$ ) compared to non-diabetic women (CF $17.9 \%$ ). This increased risk was present only in the 35-64 year age group (diabetic 19.7 vs non-diabetic $12.6 \% ; p=0.046$ ), while older diabetic women (65-74 years) had almost the same case fatality $(22.9 \%)$ as the non-diabetic women $(20.3 \%)$ $(p=0.225)$. In women with first ever stroke there was no significant difference in case fatality between the diabetic and the non-diabetic patients (17.4 vs $16.7 \% ; p=0.766)$. The mortality rates in all strokes were 339 per 100,000 per year (95\% CI 195-485) in diabetic men and 389 (95\% CI 209-569) in diabetic women. The corresponding rate in non-diabetic men was $56(95 \%$ CI 42-70) and in non-diabetic women $36(95 \%$ CI $25-47)$.

Concomitant disorders. Atrial fibrillation, hypertension, heart failure and myocardial infarction were all significantly more common in both men and women with diabetes compared with non-diabetic stroke patients. Table 5 shows the relative risks (with $95 \%$ CI) in diabetic vs non-diabetic individuals for having any of these concomitant disorders.

Population attributable risk. Figure 1 shows population attributable risk in different age groups. It varied little with age, and the overall attributable risk was $18 \%$ in men and $22 \%$ in women. If, in a sensitivity analysis, the upper and the lower limit of the prevalence of diabetes in the entire population was applied in the calculations of population attributable risks, the attributable risks ranged from 17.1 to $18.9 \%$ in men and from 20.7 to $22.6 \%$ in women.

\section{Discussion}

With more than 1,500 stroke events in diabetic patients and more than 4,800 strokes in non-diabetic subjects, this is the first population-based study in which it has been possible to estimate the incidence of stroke in a diabetic compared to a non-diabetic population with reasonable accuracy. Middle-aged diabetic patients were found to have an incidence of stroke that, in men, was 4.4 times higher and, in women, 5.8 times higher than in non-diabetic subjects. Diabetes was a major contributor to all strokes with a population attributable risk as high as around $20 \%$. Case fatality was observed to be similar in stroke patients with and without diabetes, resulting in an increase in stroke mortality among diabetic patients that was of the same magnitude as the increase in incidence. The marked excess in stroke mortality is in accordance with recent results from the Multiple Risk Factor Intervention Trial (MRFIT) in which mortality from non-haemorrhagic stroke during 10 years' follow-up was 8 times greater in diabetic than in non-diabetic men [17].

The Northern Sweden MONICA stroke register was thoroughly validated throughout the observation period. Case ascertainment was found to be satisfactory with more than $95 \%$ of all strokes being re- 
corded $[11,12,18]$. The same personnel coded stroke events during the 8 years covered by the present study, ensuring consistency over time.

Previous estimates of the relative risk of stroke in diabetic individuals have been based on cross-sectional or cohort studies of smaller populations $[2,6$, $7,19]$. Our estimate of the incidence of stroke in diabetic subjects is derived from the number of stroke patients with diabetes and the prevalence of diabetes in the same population.

Applying the WHO criteria [10], the prevalence of undiagnosed diabetes detected by oral glucose tolerance test was only slightly lower than that found in a population study in the United States (age range 2074 years). The prevalence of undiagnosed diabetes in northern Sweden was $2.6 \%$ (men and women together) and in the United States study 3.2\% [20]. Thus, the prevalence of undiagnosed diabetes is about equal to that of previously diagnosed diabetes in the community. Applying the modified 1991 WHO criteria for epidemiological studies, which do not take fasting plasma glucose levels into account [21], the prevalence of diabetes in this study would have been reduced from an overall of 6.1 to $5.7 \%$.

People who have regular contacts with a physician are less likely to participate in population screenings. A possible over-representation of diabetic patients among people not participating in the population survey is therefore possible. However, the overall non-responder rate was low in the surveys $(22 \%)$ and the impact on prevalence rates of diabetes (and calculations of population attributable risks) would be modest.

The overall prevalence of diabetes found in the present study is very similar to that observed for the same age groups in other parts of Sweden [22, 23], except that a lower prevalence in 65-74-year-old men was reported in one of the studies [23].

In a previous hospital-based study, we found $2 \%$ of stroke patients of all ages to have diabetes diagnosed during the hospital stay for stroke [9]. In the present study, 57 patients with hyperglycaemia during the acute phase of stroke were not included because it was uncertain if this reflected stress-associated hyperglycaemia in acute stroke [24] previously unknown diabetes or diabetes precipitated by the acute event. Information on diabetes was lacking for another 58 of the 6,370 stroke patients; most of these cases were fatal without any mention of diabetes in the medical records before the event. Even if all patients with hyperglycaemia during the acute event and those without information on diabetes were assumed to have diabetes, the prevalence of diabetes among stroke patients would increase from the present $24.2 \%$ to no more than $26.0 \%$ (both first and recurrent events), and it would have little influence on estimates of incidence and attack rates or population attributable risk.

In patients with first ever stroke, $22 \%$ had a known diabetes at stroke onset. In other studies, the reported prevalence of diabetes in stroke patients varies from 11 to $27 \%$ [25-31]. The variations may partly be explained by the fact that some of the studies were hospital based whereas others were community based, and that some included all strokes and some only first ever events.

As a group, diabetic patients with stroke were much dominated by those with non-insulin-dependent diabetes. This agrees with previous observations $[9,26]$. In the 35-44 year age group, however, more than $75 \%$ of patients had insulin-dependent diabetes and, in this age group, they contributed substantially to the high incidence of stroke associated with diabetes.

Haemorrhagic lesions are, in relative terms, less common in diabetic patients, than in non-diabetic stroke patients. The prevalence of diabetes in patients with subarachnoid haemorrhage was even lower than in the general population ( 0.9 vs $8.8 \%)$. A low prevalence of diabetes in patients with subarachnoid haemorrhage has also been documented by others [3-5]. We also observed a markedly lower prevalence of diabetes in subjects with intracerebral haemorrhage than in those with ischaemic stroke; this is in accordance with other reports $[5,26,31]$. However, a different picture emerges when a population approach is used to express the risk of stroke in absolute terms. As the type of stroke was not known for a substantial proportion of patients $(38 \%)$, it was not possible to accurately determine type-specific incidence. However, using the limited data available, incidence of intracerebral haemorrhage was still found to be 2 times higher in diabetic than in non-diabetic individuals (same ratio in both men and women).

In most of the other studies, diabetic stroke patients were reported to have a worse outcome compared to non-diabetic subjects $[6,8,17,32]$. In the present study, however, case fatality was only slightly higher in the diabetic patients and the difference was only statistically significant in one subgroup (women below the age of 65 years). One reason for the relatively low case fatality in diabetic stroke patients in the present study is that it covered only ages up to 75 years. Also, it may be that, following greater awareness of complications threatening diabetic stroke patients, management and survival has improved in these patients in recent years. A report from the Minnesota Heart Survey does not, however, support this view; between 1970 and 1985, case fatality did not improve in diabetic stroke patients as it did in non-diabetic patients [19].

As previously reported by other investigators [9, $28,33,34]$, diabetic stroke patients were found to have more cardiovascular disorders than non-diabetic patients. The cardiovascular disorders included were hypertension, ischaemic heart disease, cardiac failure and atrial fibrillation. These disorders are 
also more common in the general population of diabetic patients $[4,6,35,36]$ and they contribute to the increased risk of stroke in individuals with diabetes. We found concomitant disorders to be more common in diabetic women than in men, which could contribute to the higher case fatality in women.

The population attributable risk of stroke associated with diabetes was calculated to be about $20 \%$ for the ages covered by the present study. Attributable risk is a measure that is based on relative risk and proportion of the population exposed. It should be regarded as an estimate of the proportion of all stroke events that can be prevented if diabetes did not exist in the community. It should be emphasised that this is a crude measure that assumes a direct causal relationship between diabetes and stroke, and it does not take into account interactions with other risk factors. Also, if the prevalence of diabetes in the general population is underestimated, the relative risk of stroke in diabetic vs non-diabetic subjects would be increased and the population attributable risk overestimated. However, in sensitivity analyses, the population attributable risk was only slightly reduced if the upper $95 \%$ confidence limit of prevalence of diabetes in the general population was taken into consideration.

In this paper, emphasis is on crude attack and incidence rates and not age-standardised rates. Crude rates show a more "true" impact of diabetes on stroke attack and incidence rates in each age group, than age-standardised rates. Standardised to the 1989 population, the relative risks for stroke conferred by diabetes were somewhat lower, reflecting the age distribution of diabetes in the population.

Our results emphasise the importance of diabetes as a risk factor for stroke from a population perspective. If, as a theoretical exercise, the population attributable risk of approximately $20 \%$ is translated into number of strokes in the whole population of Sweden, approximately 50 strokes are directly attributable to diabetes each year in a population of 100,000 people aged 35-74 years. It is not known to what extent improved metabolic control in diabetic patients could reduce the risk of stroke, but there is certainly room for further prevention of stroke in diabetic patients, by documented measures such as stopping smoking, better hypertension control, anticoagulation treatment in patients with atrial fibrillation and improved management of symptomatic carotid disease.

Acknowledgements. The study was supported by grants from the Swedish Public Health Institute, Västerbotten County Council, the Swedish Medical Research Council (27X-07192), the Heart and Chest Foundation, King Gustav V's 80th Anniversary Fund, the Year 1987 Stroke Fund and the Joint Committee of the Northern Sweden Health Care Region.

\section{References}

1. Fuller JH, Shipley MJ, Rose G, Jarrett RJ, Keen H (1983) Mortality from coronary heart disease and stroke in relation to degree of glycaemia: the Whitehall study. BMJ 287 : 867-868

2. Biller J, Love BB (1993) Diabetes and stroke. Med Clin North Am 77: 95-110

3. Adams HP, Putman SF, Kassell NF, Torner JC (1984) Prevalence of diabetes mellitus among patients with subarachnoid haemorrhage. Arch Neurol 41: 1033-1035

4. Abbott RD, Donahue RP, MacMahon SW, Reed DM, Yano K (1987) Diabetes and the risk factor of stroke. JAMA 257: 949-952

5. Jamrozik K, Broadhurst RJ, Anderson CS, StewartWyanne EG (1994) The role of lifestyle factors in the etiology of stroke a population-based case-control study in Perth Western Australia. Stroke 25: 51-59

6. Kannel WB, McGee DL (1979) Diabetes and cardiovascular disease. The Framingham study. JAMA 241: 20352038

7. Barrett-Conner E, Khaw KT (1988) Diabetes mellitus: an independent risk factor for stroke? Am J Epidemiol 128: 116-123

8. Asplund K, Hägg E, Helmers C, Lithner F, Strand T, Wester PO (1980) The natural history of stroke in diabetic patients. Acta Med Scand 207: 417-424

9. Olsson T, Viitanen M, Asplund K, Eriksson S, Hägg E (1990) Prognosis after stroke in diabetic patients. A controlled prospective study. Diabetologia 33: 244-249

10. WHO Study Group on Diabetes Mellitus (1985) World Health Organization Technical Report Series 727. World Health Organization, Geneva

11. Asplund K, Tuomilehto J, Stegmayr B, Wester PO, Tunstall-Pedoe H (1988) Diagnostic of criteria and quality control of the registration of stroke events in the MONICA Project. Acta Med Scand [Suppl] 728: 26-39

12. Stegmayr B, Asplund K (1992) Measuring stroke in the population: quality of routine statistics in comparison with a population based stroke registry. Neuroepidemiology 11 : 204-213

13. WHO MONICA Manual (1990) Monitoring of trends and determinants in cardiovascular diseases. Cardiovascular Diseases Unit. World Health Organization, Geneva

14. Tunstall-Pedoe $H$, WHO MONICA Project Principal Investigators (1988) The World Health Organization MONICA Project: monitoring of trends and determinants in cardiovascular diseases. J Clin Epidemiol 41: 105114

15. Dean J, Dean A, Brendel K (1990) Epi Info. Version 5: a word processing, database, and statistics system for epidemiology on micro-computers. USD, Incorporated, Stone Mountain, Georgia

16. Armitage P, Berry G (1987) Statistical methods in medical research, 2nd edn. Blackwell, Oxford

17. Neaton JD, Wentworth DN, Cutler J, Stamler J, Kuller L (1993) Risk factors for death from different types of stroke. Ann Epidemiol 3: 493-499

18. WHO MONICA Project (report prepared by Asplund K, Bonita R, Kuulasmaa K, Rajakangas A-M, Feigin V, Schaedlich H, Suzuki K, Thorvaldsen P (1995) Multinational comparisons of stroke epidemiology: evaluation of case ascertainment in the WHO MONICA Stroke study. Stroke 26: 355-360

19. Sprafka JM, Virnig BA, Shahar E, McGovern PG (1994) Trends in diabetes prevalence among stroke patients and 
the effect of diabetes on stroke survival: the Minnesota Heart Survey. Diabet Med 11: 678-684

20. Harris MI, Hadden WC, Knowler WC, Bennett PH (1987) Prevalence of diabetes and impaired glucose tolerance and plasma glucose levels in US population aged 20-74 yr. Diabetes 36: 523-534

21. Bennett $P$ (1991) Classification and diagnosis of diabetes mellitus. In: Williams JP (ed) Textbook of diabetes. Blackwell, Oxford, pp 37-44

22. Lundman B (1993) Utvärdering av vårdprogram för diabetes i Medelpad. Rapport no.34. Primärvårdens utvecklingsenhet i Medelpad. Sundsvall, pp 1-50

23. Andersson DK, Svärdsudd K, Tibblin G (1991) Prevalence and incidence of diabetes in a Swedish community 19721987. Diabet Med 8: 428-434

24. Gray CS, Tayler R, French JM et al. (1987) The prognostic value of stress hyperglycaemia and previously unrecognized diabetes in acute stroke. Diabet Med 4: 237-240

25. Jerntorp P, Berglund G (1992) Stroke registry in Malmö, Sweden. Stroke 23: 357-361

26. Lithner F, Asplund K, Eriksson S, Hägg E, Strand T, Wester PO (1988) Clinical characteristics in diabetic stroke patients. Diabete Metab 14: 15-19

27. Toni D, Sacchetti ML, Argentino C et al. (1992) Does hyperglycaemia play a role on the outcome of acute ischaemic stroke patients? J Neurol 239: 382-386

28. Alter M, Friday G, Sobel E, Lai SM (1993) The Lehigh Valley Recurrent Stroke Study: description of design and methods. Neuroepidemiology 12: 241-248
29. Sandercock PAG, Warlow CP, Jones LN, Starkey IR (1989) Predisposing factors for cerebral infarction: the Oxfordshire community stroke project. BMJ 298: 75-80

30. von Arbin M, Britton M, de Faire U, Tisell Å (1985) Circulatory manifestations and risk factors in patients with acute cerebrovascular disease and in matched controls. Acta Med Scand 218: 373-380

31. Jørgensen HS, Nakayama H, Raaschou HO, Olsen TS (1994) Stroke in patients with diabetes. The Copenhagen stroke study. Stroke 25: 1977-1984

32. van Kooten F, Hoogerbrugge N, Naarding P, Koudstaal PJ (1993) Hyperglycemia in the acute phase of stroke is not caused by stress. Stroke 24: 1129-1132

33. Fritz VU, Bilchik T, Levien LJ (1987) Diabetes as risk factor for transient ischaemic attacks opposed to stroke. Eur J Vasc Surg 1: 259-262

34. Carlberg B, Asplund K, Hägg E (1991) Factors influencing admission blood pressure levels in patients with acute stroke. Stroke 22: 527-530

35. Kuusisto J, Mykkänen L, Pyörälä K, Laakso M (1994) Noninsulin dependent diabetes and its metabolic control are important predictors of stroke in elderly subjects. Stroke 25: 1157-1164

36. Chukwuma CS, Tuomilehto J (1993) Diabetes and the risk of stroke. J Diabetes Complications 7: 250-262 